\title{
Tree cover change proves stability and instability in tropical ecosystems
}

\author{
Chandrakant Singh ${ }^{1,2, *}$, Ruud van der Ent ${ }^{3,4}$, Lan Wang-Erlandsson ${ }^{1,2}$, Ingo Fetzer ${ }^{1,2}$ \\ ${ }^{1}$ Stockholm Resilience Centre, Stockholm University, Stockholm, Sweden \\ ${ }^{2}$ Bolin Centre for Climate Research, Stockholm University, Stockholm, Sweden \\ ${ }^{3}$ Department of Water Management, Faculty of Civil Engineering and Geosciences, Delft \\ University of Technology, Delft, The Netherlands \\ ${ }^{4}$ Department of Physical Geography, Faculty of Geosciences, Utrecht University, Utrecht, The \\ Netherlands \\ * Author to whom any correspondence should be addressed \\ Email: chandrakant.singh@su.se
}

This paper is a non-peer reviewed preprint submitted to EarthArXiv. 


\title{
Tree cover change proves stability and instability in tropical ecosystems
}

\author{
Chandrakant Singh ${ }^{1,2, *}$, Ruud van der Ent ${ }^{3,4}$, Lan Wang-Erlandsson ${ }^{1,2}$, Ingo Fetzer ${ }^{1,2}$ \\ ${ }^{1}$ Stockholm Resilience Centre, Stockholm University, Stockholm, Sweden \\ ${ }^{2}$ Bolin Centre for Climate Research, Stockholm University, Stockholm, Sweden \\ ${ }^{3}$ Department of Water Management, Faculty of Civil Engineering and Geosciences, Delft \\ University of Technology, Delft, The Netherlands \\ ${ }^{4}$ Department of Physical Geography, Faculty of Geosciences, Utrecht University, Utrecht, The \\ Netherlands \\ * Author to whom any correspondence should be addressed \\ Email: chandrakant.singh@su.se
}

The resilience of terrestrial ecosystems is predominantly based on space-for-time substitution. This substitution assumes that the contemporary spatial frequency distribution of ecosystems' tree cover structure holds across time. However, this assumption is problematic, especially when temporal dynamics and adaptations are increasingly important to explicitly account for ongoing rapid changes across time. Here we empirically study ecosystems' stability and adaptation dynamics over the last two decades by examining tree cover change (UTC) and root zone storage capacity $\left(S_{\mathrm{r}}\right.$; buffer capacity towards water-stress). We find that ecosystems at both high $(>\mathbf{7 5 \%})$ and low $(<10 \%)$ tree cover experience limited $\triangle T C$ - signifying stability. Whereas considerable $\triangle \mathrm{TC}$ is observed at intermediate (30-60\%) tree cover ecosystems indicating instability. Our results suggest that stable ecosystems retain their structural integrity by instigating investment in their subsoil structure (i.e., $S_{\mathrm{r}}$ ). In contrast, unstable ecosystems are unable to exploit the same level of adaptation as stable ecosystems, thereby making them prone to transitions. Furthermore, ignoring this adaptive capacity can largely underestimate the resilience of the forest ecosystems, which we find in the case of the Congo rainforests. This study emphasises the importance of temporal dynamics and adaptation of ecosystems in inferring and assessing the risk of forest-savannah transitions under change. 


\section{Main}

Climate change and deforestation reduces the resilience of rainforest ecosystems ${ }^{1,2}$, and thus compromise their capacity to remain forests despite various perturbations ${ }^{3,4}$. Resilience can be quantified and analysed by constructing a 'stability landscape' (Fig. 1), in which valleys ('basins of attraction') represent 'stable states' and hilltops represent 'unstable states' under transition. Resilience is then measured as the width of the basin of attraction around a stable state, which erodes towards bifurcation points (i.e., a point where stable and unstable states collide, becoming unstable) $)^{1,2}$ (Fig. 1a). Within a basin of attraction, stabilising feedbacks help the ecosystem retain its structural and functional characteristics against perturbations ${ }^{5}$. The ecosystem will eventually return to its native stable state ('minimum' of the basin) when perturbations on the system are released (Fig. 1b,c). Beyond a basin of attraction, i.e., trespassing a threshold ('maximum' of the basin), self-amplifying feedbacks will instead shift an ecosystem to an alternative stable state ${ }^{1,5}$. A better understanding of stability and resilience is helpful to evaluate the potential of ecosystem adaptation and systemic risks under future (climatological or non-climatological) modifications to their conditions ${ }^{6}$.

Due to the lack of analysis of dynamics through time series ${ }^{7,8}$, our present understanding about the stability landscape of the terrestrial tropical ecosystems is based on the frequency distribution of tree cover ${ }^{1,9-11}$, essentially making a space-for-time assumption (Fig. 1a). According to this methodology, frequency distribution determines the size (i.e., width and depth) of the basin of attraction in the conceptual stability landscape, which is then interpreted to be ecosystems stability (deep basin, more stable and vice versa) and resilience (wider basin, more resilient and vice versa) across time ${ }^{1,12}$ (Fig. 1a). The availability of longer time series of remote sensing data now allow for a better representation of these ecological states and resilience across time ${ }^{8,13}$.

Here, for the first time, to our knowledge, a time series of tree cover spanning two decades is analysed to investigate rainforest stability and resilience. It is known that the ecosystem's response towards any perturbations should be captured in the transient state (i.e., as tree cover change $(\triangle \mathrm{TC}))$ of the ecosystem ${ }^{14,15}$. We hypothesise that the transient state of the ecosystem should resemble the stability landscape found by the space-for-time assumption (Fig. 1a). Thus, a highly resilient ecosystem will not show considerable $\triangle \mathrm{TC}$ over time, whereas a lowly resilient ecosystem will. 


\section{a}

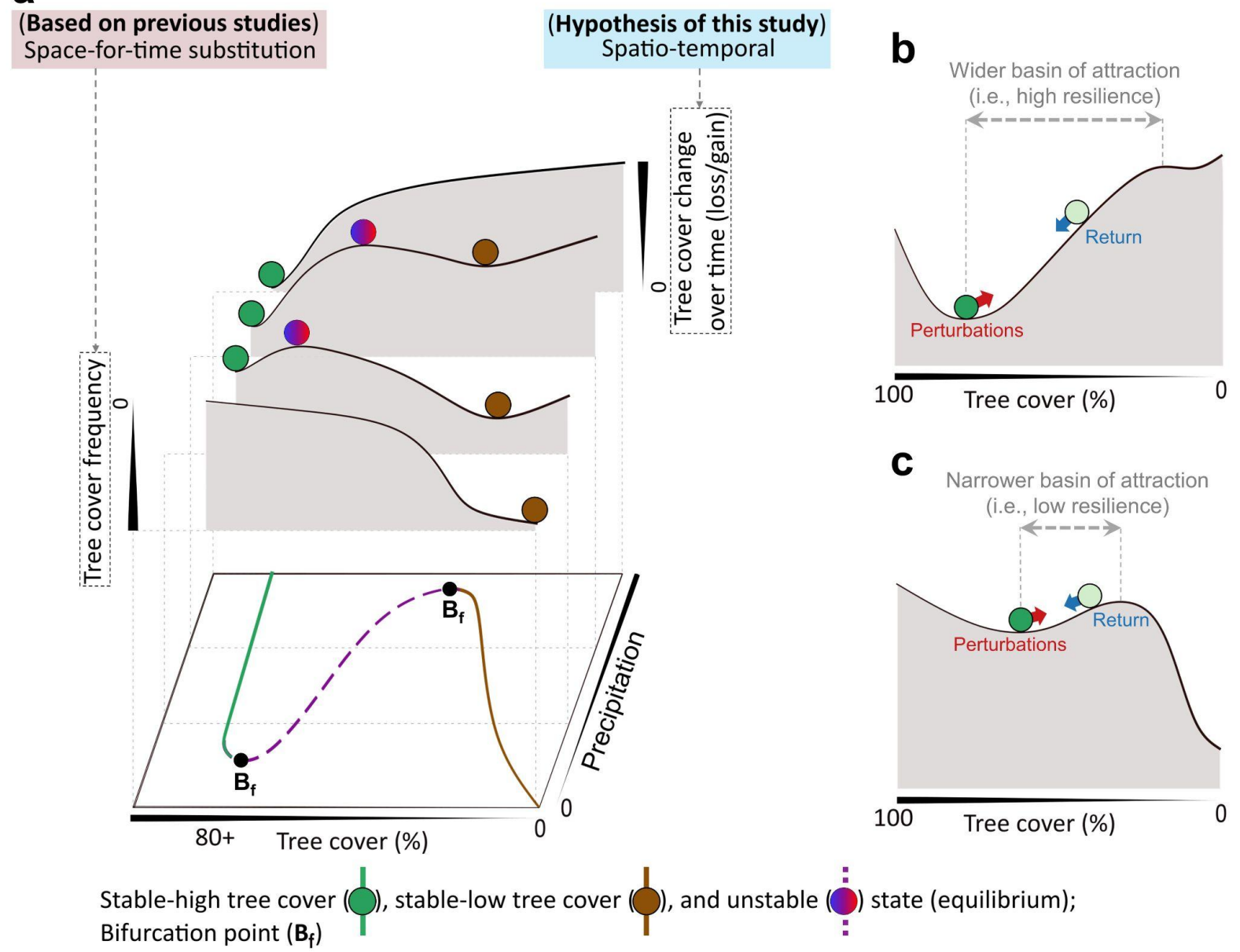

Fig. 1 | Stability landscape of ecosystems across different mean precipitation ( $\left.\mathrm{mm}_{\mathbf{y r}} \mathbf{r}^{-1}\right)$. (a) The landscape is, originally, based on the frequency distribution of the tree cover (space-for-time assumption ${ }^{1,9-11}$ ). This study substitutes 'tree cover frequency' with magnitudes of 'tree cover change over time' for South America and Africa (spatio-temporal) across different classes of precipitation, which we hypothesise should resemble the original landscape. Stable and unstable states (i.e., equilibria) correspond to the valleys (i.e., local minima) and hilltops (i.e., local maxima) in the stability landscapes, respectively. (b,c) Resilience of an individual ecosystem across the stability landscape is represented as the width of the basin of the attraction around a stable state, which declines towards the bifurcation points (i.e., a point where stable and unstable states collide; depicted in a,b). Perturbations push the ecosystem towards the hilltop, whereas the ecosystem returns to its stable state when these perturbations are released.

Our hypothesis suggests a correlation between $\triangle \mathrm{TC}$ and resilience of the ecosystems. Previous research overlooks any such correlation and only considers the hydroclimate specifically mean precipitation $(\bar{P})$ - when quantifying forest resilience ${ }^{1,16}$. Recent insights, however, hint towards the necessity to also incorporate the buffering capacity of the forest ecosystems, an aspect that is often lacking when representing the ecohydrology of tropical ecosystems ${ }^{13,17,18}$. To include this buffering capacity, we use root zone storage capacity $\left(S_{\mathrm{r}}\right)$ representing the maximum amount of the subsoil moisture available to ecosystems buffering water shortage during dry periods ${ }^{17,19}$ to quantify the resilience of the ecosystem. This aspect 
acknowledges that ecosystems respond to water-stress by actively investing in their aboveand below-ground structures to maximise their hydrological benefits ${ }^{17}$. Thus, the resulting resilience metric, by also explicitly considering the ecosystems' adaptive and buffering strategies, should be consistent with actual $\triangle \mathrm{TC}$.

\section{Tree cover change in relation to stability equilibria}

Our spatio-temporal analysis consistently shows low $\triangle \mathrm{TC}$ for ecosystems at both high $(>75 \%)$ and low $(<10 \%)$ tree cover, whereas high $\triangle \mathrm{TC}$ is observed for ecosystems at intermediate (30-60\%) tree cover (Fig. 2a,c). A low $\triangle \mathrm{TC}$ for both high and low tree cover ecosystems can be the result of either a minimal perturbation on the ecosystem over the last two decades (2000-2019), or a robust adaptive mechanism that is able to offset the experienced perturbations without considerable change in the ecosystem structure ${ }^{17}$, which we, therefore, perceive as 'stable'. Conversely, a high $\triangle \mathrm{TC}$ at intermediate tree cover (Fig. $2 \mathrm{a}, \mathrm{c})$ implies that the ecosystems in these ranges have been potentially influenced by either strong perturbations ${ }^{20}$ (e.g., deforestation) causing significant changes to their ecosystem structure, or the adaptive mechanism has modified the ecosystem structure to efficiently utilise available resources ${ }^{17}$ (e.g., tree mortality under water stress to make more moisture available for the rest of the ecosystem, or tree growth under the influence of wetter climate ${ }^{21}$ ), which could result in them undergoing the observed regime shift ${ }^{1,12}$. Thus, we consider such ecosystems with relatively high structure changes (i.e., $\triangle \mathrm{TC}$ ) as 'unstable'. These spatio-temporal patterns against different $\bar{P}$ levels (Fig. 2a,c), therefore, further strengthen the presence of stability and instability, which previous studies observed using a space-for-time assumption $^{1,9-11}$, can also manifest as actual $\triangle \mathrm{TC}$ over time across the broader tree cover structures.

A closer look at the alternative stable states (i.e., stable-low and -high tree cover bins representing a series of numerical ranges highlighted in dark brown and green, respectively, in Fig. 2a,c and spatially highlighted in Fig. 2b,d) reveals certain dissimilarities across the precipitation classes. Stable-high tree cover bins decrease gradually with decreasing $\bar{P}$ (Fig. $2 \mathrm{a}, \mathrm{c})$, therefore, implying the inability of the forest ecosystems to maintain their dense structural characteristics under drier conditions ${ }^{17}$, which makes them undergo a self-propagating shift to a savannah-like open-canopy structure ${ }^{1,22}$. Reversely, stable-low tree cover bins decrease with increasing $\bar{P}$ (Fig. 2a,c). Here, an increase in wetter conditions in the 
ecosystem helps suppress fire and prevents fire-driven seedling mortality ${ }^{22}$, and drives more soil water storage under a wetter climate $^{23}$, thus promoting forest growth and colonisation ${ }^{1,24}$. Nevertheless, the shifting potential, in both these cases, generally manifests itself as a relatively high $\Delta \mathrm{TC}$ within the stable extent (e.g., relatively high $\Delta \mathrm{TC}$ for $\bar{P}<985 \mathrm{~mm} \mathrm{yr}^{-1}$ for South America, and $\bar{P}<1,468 \mathrm{~mm} \mathrm{yr}^{-1}$ for Africa at a tree cover $>70 \%$ in Fig. 2), with some exceptions (Supplementary Fig. 2).

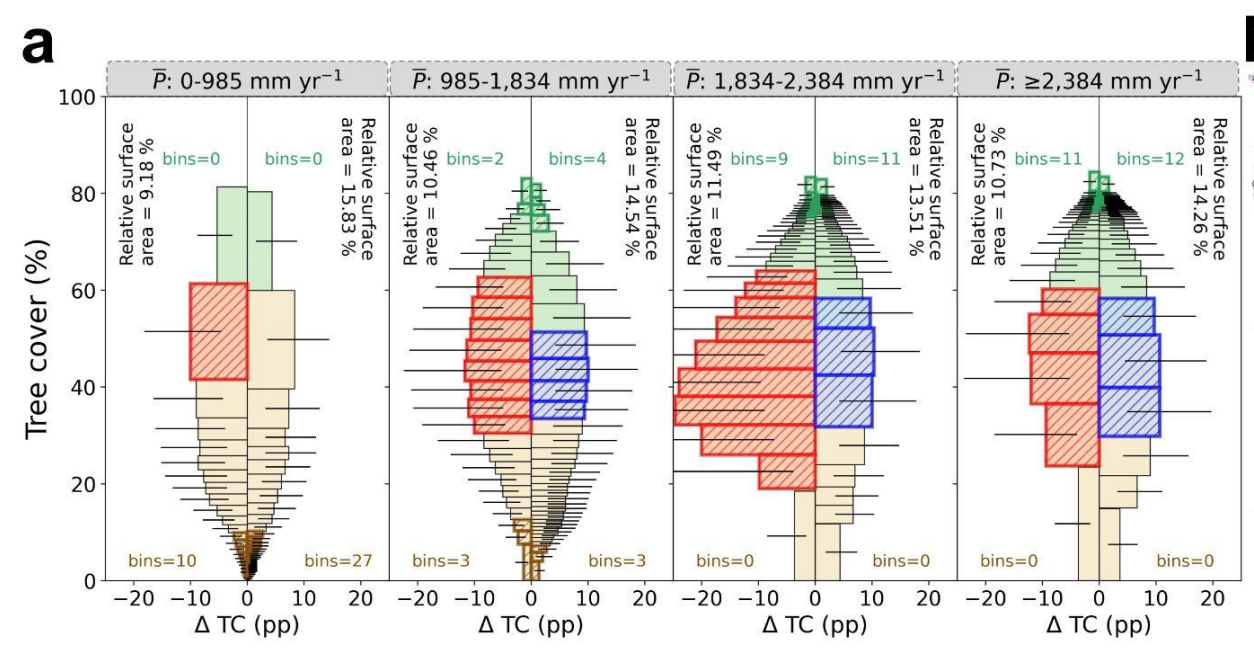

b
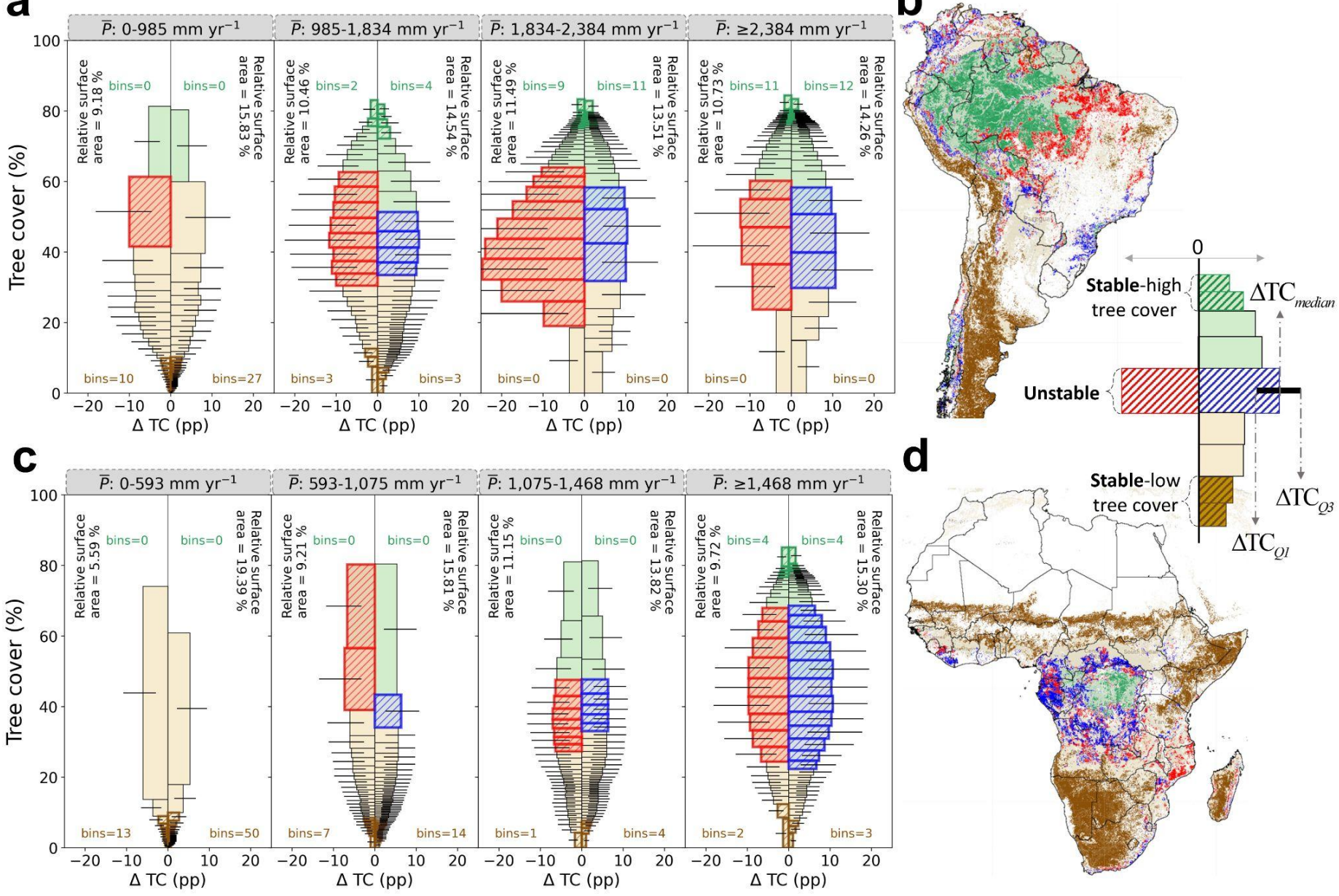

Fig. 2 | Determining the stability landscape of the tropical ecosystem. The landscape for (a,b) South America and (c,d) Africa are analysed using the tree cover $(\%)$, tree cover change $(\triangle \mathrm{TC}$; percent point $(\mathrm{pp}))$ over the last two decades (from 2000-2019; see methods), and mean precipitation $\left(\bar{P}\left(\mathrm{~mm} \mathrm{yr}^{-1}\right)\right.$; from 2000-2019). The total samples are equally divided into four $\bar{P}$ classes. Here, each individual bin within each $\bar{P}$ class corresponds to 2,500 samples. From all these bins, the one with the least $\triangle \mathrm{TC}$ is considered stable, and the one with the most $\triangle \mathrm{TC}$ is unstable (see methods). These stable bins at low (dark brown) and high (dark green) tree cover in $(\mathrm{a}, \mathrm{c})$ are spatially plotted in $(\mathrm{b}, \mathrm{d})$. The unstable bins on either side of $\Delta \mathrm{TC}=0$ correspond to tree cover loss (red) or gain (blue). The relative surface area in $(a, c)$ represents the portion of total sample surface area (separately for South America and Africa) on either side of the $\Delta \mathrm{TC}=0$. The tree cover extent of stable and unstable bins in $(\mathrm{a}, \mathrm{c})$ are spatially plotted in $(\mathrm{b}, \mathrm{d})$. The white regions in $(\mathrm{b}, \mathrm{d})$ correspond to excluded land cover (Supplementary Fig. 1d). 
Interestingly, we also observe that for most of the $\bar{P}$ classes, the extent of the unstable bins (i.e., ranges highlighted in red and blue in Fig. 2a,c) is almost similar for both tree cover loss and gain segments. This equal potential for both tree cover loss and gain at intermediate tree cover was already hypothesised in a space-for-time based approach ${ }^{1}$ (Fig. 1a), and is confirmed by observable evidence at field scale (e.g., forest loss under increasingly drier conditions $^{25}$ or increasing forest growth under El Niño-southern oscillation influenced wet conditions $^{21}$ ). Our spatio-temporal approach provides empirical evidence to this $\triangle \mathrm{TC}$ potential at continental scales, as well as proof that the ecosystem change leading to a regime shift is indeed intensified at intermediate tree $\operatorname{cover}^{1}$ (Fig. 2). This change in tree cover structure across different $\bar{P}$ levels, thus, seem to follow our spatio-temporal hypothesis (Fig. 1a and 2).

But why can forest ecosystems maintain stability at different $\bar{P}$ levels and how does that relate to $\Delta \mathrm{TC}$ (Fig. 2)? The results from our $S_{\mathrm{r}}$ analysis show that forest ecosystems maintain their tree cover structure at decreasing $\bar{P}$ by increasing investment in their subsoil structure ${ }^{17}$ (Fig. 3). When going from high to low tree cover, we clearly observe a steep increase in $S_{\mathrm{r}}$ with decreasing $\bar{P}$ within the stability extent of tree cover from $85 \%$ to $75 \%$ (Fig. 3a) in South America. For Africa, although only a small portion of the forest is in this comparatively low $S_{\mathrm{r}}$ stable state (Fig. 3b), we still observe a steep increase in $S_{\mathrm{r}}$ near the stable-high tree cover state. Here, the least $\Delta \mathrm{TC}$ within this stability extent of stable-high tree cover ecosystems' reveals that forests respond to the change in $\bar{P}$ by investing in their $S_{\mathrm{r}}$ (Fig. 2 and 3). This $S_{\mathrm{r}}$ investment in reality is the vertical and lateral growth of roots which allows for more subsoil moisture storage, thereby assisting the forest ecosystems' to maintain their (stable) dense tree cover structure even under hydroclimatic stresses ${ }^{17}$. However, this balancing feedback of $S_{r}$ investment to keep the ecosystems in a stable-high tree cover state starts to change as we move to the intermediate tree cover.

At (unstable) intermediate tree cover, we find $\triangle \mathrm{TC}$ to gradually increase and maximise around $40-50 \%$ tree cover (Fig. 2). We also find that the steep increase in $S_{\text {r }}$ gradually maximises around the 70-60\% tree cover and remains unchanged between $60-30 \%$ tree cover (Fig. 3), thus suggesting causation between maximum $S_{\mathrm{r}}$ investment and changes to ecosystem structure ${ }^{17}$. When analysing the changes to the forest ecosystems' structure against varying levels of drought and fire stress at local scale (Supplementary Fig. 3 and 4; see 
Supplementary Methods), we observe that unstable state forests - in comparison to stable-high tree cover ecosystems - have often maximised their $S_{\mathrm{r}}$ investment and show deterioration to a savannah-like state. These deteriorations are not sudden but gradual over time, thus, suggesting that there exists a certain maximum investment potential beyond which the shift from forest to a savannah state becomes eminent ${ }^{17}$, which manifests itself as relatively high $\triangle \mathrm{TC}$ over time for the unstable forest ecosystems (Fig. 2, Supplementary Fig. 3 and 4). Considering $S_{\mathrm{r}}$ along with $\bar{P}$, therefore, has allowed us to evaluate the invisible buffering responses of forest ecosystems specifically catered towards efficiently optimising the available water resources and modifying their tree cover structure, and thus is able to manifest the shifts between the transient (stable and unstable) states as different magnitudes of $\triangle \mathrm{TC}$.

a



South America

\section{Tree cover gain}

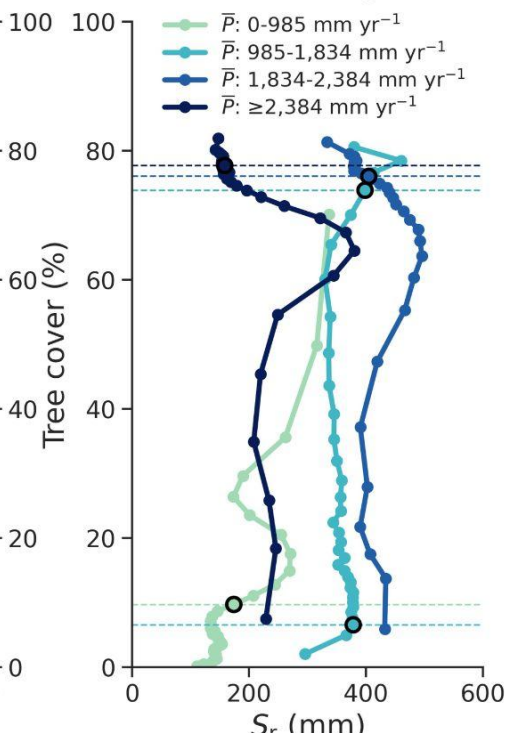

b

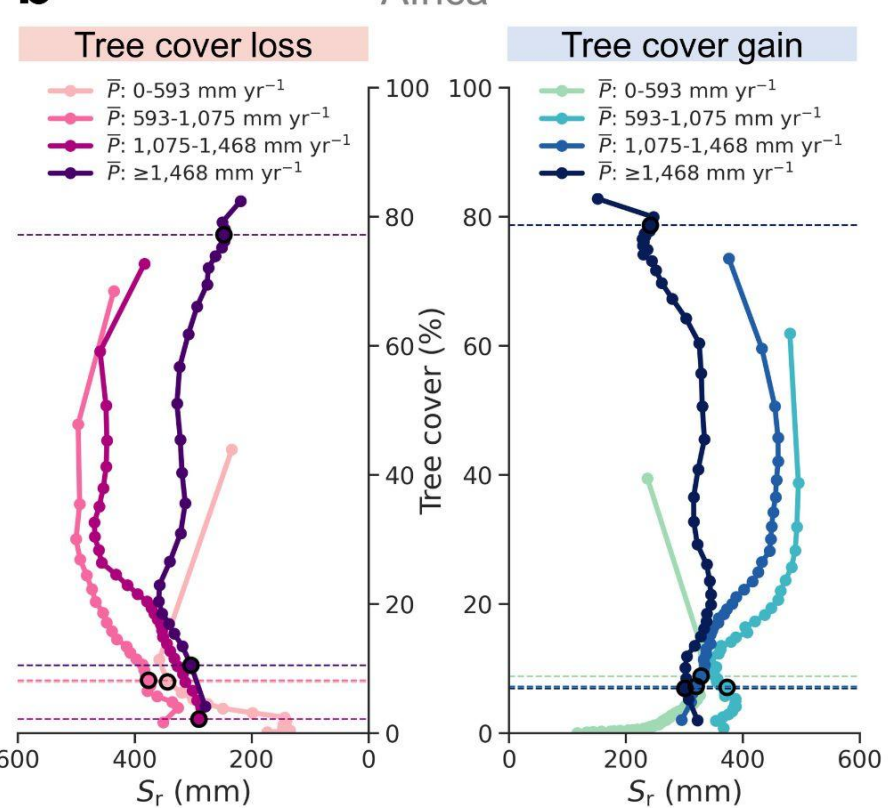

Fig. 3 | Relationship between mean precipitation $(\bar{P})$ and root zone storage capacity $\left(S_{\mathrm{r}}\right)$ for (a) South America and (b) Africa. The solid lines correspond to median $S_{\mathrm{r}}$ for the bins of tree cover loss (left) and gain (right) in Fig. 2. The points on the solid lines represent the centre of the individual bins. The (horizontal) dashed lines correspond to the minimum and maximum extent of the stable-high and -low tree cover ecosystems, respectively, as defined in Fig. 2a,c.

\section{Resilience of the rainforest}

Resilience based on logistic regression predicts the probability of the occurrence of a forest ecosystem (tree cover $>50 \%$ ) as a function of both $\bar{P}$ and $S_{\mathrm{r}}$ for respective continents (Supplementary Table 1 and 2; see methods). It predicts resilience between a scale of 0 to 1 , where 1 represents the highest probability of finding forest - interpreted as a highly resilient 
forest ecosystem against perturbations - given the recent decades of $\bar{P}$ and $S_{\mathrm{r}}$ estimates (Fig. 4). This resilience estimate suggests that the central and central-western parts of Amazon rainforests in South America, and a major portion of the central Congo rainforests in Africa are most resilient. Whereas, the least resilient forests are located in the central-eastern and southeastern corridor of Amazon rainforest, and northern and southern part of Congo rainforest (Fig. 4), which are vulnerable to a forest-savanna transition under future change to their environmental conditions ${ }^{1}$.

The $\bar{P}+S_{\mathrm{r}}$-based resilience metric shows that the resilience of a large portion of the Congo rainforest is higher than previously presumed (based on $\bar{P}$ only) ${ }^{1,16}$, whereas the resilience of Amazon rainforests shows minor differences (Fig. 4 and Supplementary Fig. 5). Due to the unique evolutionary history of their respective ecology and climatology ${ }^{26}$, high wet-season precipitation has allowed for Amazonian rainforests species to have a larger subsoil storage (i.e., $S_{\mathrm{r}}$ ) to buffer the water-deficit than the Congo rainforests ${ }^{23,27}$. The grass species in Congo rainforests, on the other hand, have evolved to be highly water-efficient ${ }^{28}$, which reduces the competitiveness between trees and grasses for moisture uptake ${ }^{17}$, thereby increasing the resilience of the overall rainforest ecosystem, even with low $S_{\mathrm{r}}$, against water-deficit. Including $S_{\mathrm{r}}$ in our resilience metric, therefore, has allowed us to capture this grass species-induced drought coping strategy in Congo rainforests, which otherwise is hard to detect with just $\bar{P}$. Nevertheless, the resilience of both rainforest ecosystems are both declining due to increasing regional climatic risks ${ }^{29}$, and combined feedbacks from local deforestation and human-induced fires ${ }^{3,4}$.

Validation with actual $\Delta$ TC shows that the $\bar{P}+S_{\mathrm{r}}$-based resilience estimates perform better than only the $\bar{P}$-based resilience (Supplementary Fig. 6). This performance based on $\triangle \mathrm{TC}$ further strengthens our original hypothesis that the lower the $\triangle \mathrm{TC}$, the more resilient the ecosystem and vice versa (Fig. 1a and Supplementary Fig. 6). Although $\bar{P}$ is an important variable defining the broad influence of the water cycle of the ecosystem, considering $S_{\mathrm{r}}$ as well includes local-scale ecosystem adaptation ${ }^{17}$, which is essential for forests to buffer and withstand hydroclimatic changes, and is thus able to better represent the resilience of the rainforest ecosystems (Supplementary Table 1). This better representation of the ecosystem resilience can, therefore, play a crucial role for management and conservation efforts ${ }^{30}$. 



Fig. 4 Resilience of the rainforest ecosystem. The resilience estimates are derived using the logistic regression based on $\bar{P}$ and $S_{\mathrm{r}}$ for both (a) South America and (b) Africa. Here, a value of one implies a forest ecosystem with the highest resilience, and zero implies a forest ecosystem with the lowest resilience. Comparing the two resilience metrics, we observed that by considering only $\bar{P}$ (in resilience calculation), the resilience estimates show considerable differences for the Amazon and Congo rainforests (exact difference in Supplementary Fig. 5). Regions with tree cover $\leq 50 \%$ and human-influenced land use (see methods) are masked.

We conclude that our observation-based spatio-temporal approach analyses $\Delta \mathrm{TC}$ over the last two decades and provides empirical evidence of alternative stable and unstable states in the tropical terrestrial ecosystem of South America and Africa. We observe low $\triangle \mathrm{TC}$ for the ecosystems at $>75 \%$ and $<10 \%$ tree cover, which we define as stable ecosystems. In contrast, high $\triangle \mathrm{TC}$ manifests itself at intermediate tree cover of $30-60 \%$, which we deem as unstable as ecosystems in these ranges are undergoing regime shifts. The tree cover ranges of stability and instability, thus, resembles the stability landscape of the previous space-for-time substitution based approach. Analysing spatio-temporal patterns with $\mathrm{S}_{\mathrm{r}}$ suggests a trade-off between stability and $\triangle \mathrm{TC}$, which reveals that forest ecosystems maintain stability by investing in their subsoil resources. However, maximising this investment potential leads to forest ecosystems undergoing regime shifts - manifesting as $\triangle \mathrm{TC}$ - towards oncoming perturbations, which otherwise can not be easily explained by only $\bar{P}$-based space-for-time 
approach. Only by modifying the existing, commonly used, $\bar{P}$-based resilience metric with an extended $\bar{P}+S_{\text {r }}$ metric, we consider both the influence of hydroclimate (i.e., $\bar{P}$ ) and the adaptive capacity of the ecosystem (i.e., $S_{\mathrm{r}}$ ) in defining the resilience of the rainforest ecosystems. Comparing the two resilience metrics, we find that the previous metric underestimates the resilience for a large part of Congo rainforests. Furthermore, the $\bar{P}+S_{\mathrm{r}}$ resilience metric shows better consistency with actual $\triangle \mathrm{TC}$, thus strengthening its performance over the $\bar{P}$-based metric. Overall, this study accounts for the ecosystems temporal and adaptation dynamics which are becoming increasingly important to assess the transient state of the ecosystems under rapidly changing local and global environmental conditions.

\section{References}

1. Hirota, M., Holmgren, M., Van Nes, E. H. \& Scheffer, M. Global Resilience of Tropical Forest and Savanna to Critical Transitions. Science 334, 232-235 (2011).

2. van Nes, E. H. et al. What Do You Mean, 'Tipping Point'? Trends Ecol. Evol. 31, 902-904 (2016).

3. Davidson, E. A. et al. The Amazon basin in transition. Nature 481, 321-328 (2012).

4. Malhi, Y. et al. Climate Change, Deforestation, and the Fate of the Amazon. Science 319, 169-172 (2008).

5. Holling, C. S. Resilience and Stability of Ecological Systems. Annu. Rev. Ecol. Syst. 4, 1-23 (1973).

6. Anderegg, W. R. L., Trugman, A. T., Badgley, G., Konings, A. G. \& Shaw, J. Divergent forest sensitivity to repeated extreme droughts. Nat. Clim. Change 10, 1091-1095 (2020).

7. Cole, L. E. S., Bhagwat, S. A. \& Willis, K. J. Recovery and resilience of tropical forests after disturbance. Nat. Commun. 5, 3906 (2014).

8. Damgaard, C. A Critique of the Space-for-Time Substitution Practice in Community Ecology. Trends Ecol. Evol. 34, 416-421 (2019).

9. Staver, A. C., Archibald, S. \& Levin, S. A. The Global Extent and Determinants of Savanna and Forest as Alternative Biome States. Science 334, 230-232 (2011).

10. Staver, A. C., Archibald, S. \& Levin, S. Tree cover in sub-Saharan Africa: Rainfall and fire constrain forest and savanna as alternative stable states. Ecology 92, 1063-1072 (2011).

11. Dantas, V. de L., Hirota, M., Oliveira, R. S. \& Pausas, J. G. Disturbance maintains alternative biome states. Ecol. Lett. 19, 12-19 (2016).

12. Scheffer, M. et al. Early-warning signals for critical transitions. Nature 461, 53-59 (2009).

13. Reyer, C. P. O. et al. Forest resilience and tipping points at different spatio-temporal scales: approaches and challenges. J. Ecol. 103, 5-15 (2015).

14. Wieczynski, D. J. et al. Climate shapes and shifts functional biodiversity in forests worldwide. Proc. Natl. Acad. Sci. 116, 587-592 (2019).

15. Heimann, M. \& Reichstein, M. Terrestrial ecosystem carbon dynamics and climate feedbacks. Nature 451, 289-292 (2008).

16. Staal, A. et al. Forest-rainfall cascades buffer against drought across the Amazon. Nat. Clim. Change 8, 539-543 (2018).

17. Singh, C., Wang-Erlandsson, L., Fetzer, I., Rockström, J. \& Ent, R. van der. Rootzone storage capacity reveals drought coping strategies along rainforest-savanna transitions. Environ. Res. Lett. 15, 124021 (2020).

18. van Oorschot, F., van der Ent, R. J., Hrachowitz, M. \& Alessandri, A. Climate-controlled root zone parameters show potential to improve water flux simulations by land surface models. Earth Syst. Dyn. 12, 725-743 (2021). 
19. Wang-Erlandsson, L. et al. Global root zone storage capacity from satellite-based evaporation. Hydrol. Earth Syst. Sci. 20, 1459-1481 (2016).

20. Sutherland, I. J. et al. Undervalued and under pressure: A plea for greater attention toward regulating ecosystem services. Ecol. Indic. 94, 23-32 (2018).

21. Holmgren, M., López, B. C., Gutiérrez, J. R. \& Squeo, F. A. Herbivory and plant growth rate determine the success of El Niño Southern Oscillation-driven tree establishment in semiarid South America. Glob. Change Biol. 12, 2263-2271 (2006).

22. Moser, B., Temperli, C., Schneiter, G. \& Wohlgemuth, T. Potential shift in tree species composition after interaction of fire and drought in the Central Alps. Eur. J. For. Res. 129, 625-633 (2010).

23. Guan, K. et al. Photosynthetic seasonality of global tropical forests constrained by hydroclimate. Nat. Geosci. 8, 284-289 (2015).

24. Uriarte, M., Muscarella, R. \& Zimmerman, J. K. Environmental heterogeneity and biotic interactions mediate climate impacts on tropical forest regeneration. Glob. Change Biol. 24, e692-e704 (2018).

25. McAlpine, C. A. et al. Forest loss and Borneo's climate. Environ. Res. Lett. 13, 044009 (2018).

26. Morley, R. J. Origin and evolution of tropical rain forests. (John Wiley \& Sons, 2000).

27. Zhou, L. et al. Widespread decline of Congo rainforest greenness in the past decade. Nature 509, 86-90 (2014).

28. Still, C. J., Berry, J. A., Collatz, G. J. \& DeFries, R. S. Global distribution of C3 and C4 vegetation: Carbon cycle implications. Glob. Biogeochem. Cycles 17, 6-1-6-14 (2003).

29. Phillips, O. L. et al. Drought Sensitivity of the Amazon Rainforest. Science 323, 1344-1347 (2009).

30. Newton, A. C. Biodiversity Risks of Adopting Resilience as a Policy Goal. Conserv. Lett. 9, 369-376 (2016).

\section{Methods}

\section{Study area}

This paper focuses on the tropical ecosystems of South America and Africa, but the whole study area is slightly larger: $12^{\circ} \mathrm{N}-50^{\circ} \mathrm{S}$ for South America and $20^{\circ} \mathrm{N}-35^{\circ} \mathrm{S}$ for Africa. We have used a global administrative database from the Food and Agriculture Organisation (FAO; http://www.fao.org/geonetwork/) to define geographical boundaries for each country and do not have any political intentions behind our research.

\section{Data}

We used remotely-sensed gauge-corrected precipitation and evaporation data for our analysis. The daily estimates of precipitation were obtained from the Climate Hazards Group InfraRed Precipitation with Station data (CHIRPS) $)^{31}$ at $0.05^{\circ}$ spatial resolution for the years 2000-2019. Furthermore, evaporation in this paper is defined as the sum of all evaporative moisture from the soil and terrestrial vegetation, including those from interception ${ }^{32}$. The evaporation datasets chosen for this study were free from any prior assumptions related to biome-dependent parameterisation and soil layer depth, and were either validated or derived 
from actual evaporation estimates (e.g., FLUXNET sites). This limitation narrowed our prospect of using the available evaporation datasets. Nevertheless, we created an equally-weighted ensemble of evaporation using three datasets: (i) Breathing Earth System Simulator $(B E S S)^{33}$ (ii) Penman-Monteith-Leuning (PML) ${ }^{34}$, and (iii) FLUXCOM-RS ${ }^{35}$. While $\mathrm{i}$ and ii were obtained at $0.5^{\circ}$, iii was obtained at $0.083^{\circ}$ spatial resolution. All three evaporation datasets were obtained at a monthly timescale for the years 2001-2012. We downscaled these datasets from monthly to daily timescale using the daily estimate of the ERA $5^{36}$ evaporation at $0.25^{\circ}$ spatial resolution.

The above-ground structure of the ecosystem was analysed using the remotely-sensed MOD44B (version 6) annual tree cover (TC) dataset ${ }^{37}$ at a fine resolution of $250 \mathrm{~m} \times 250 \mathrm{~m}$ for the years 2000-2019. Here, a TC value of 50\% would represent a ground coverage of 50\% by the canopy in the whole pixel. Furthermore, we removed the pixels with human land use and non-terrestrial land cover using the European Space Agency's (ESA) Globcover land-use classification at $300 \mathrm{~m}$ resolution to minimise the human influence on this analysis. Ultimately, all the mentioned above datasets were spatially interpolated to $250 \mathrm{~m}$ using bilinear interpolation, except for the land-use dataset, which was interpolated using nearest-neighbour interpolation.

\section{Spatio-temporal approach for determining ecosystem states}

To evaluate these stable/unstable states, a sample size $(n)$ of $1,000,000$ pixels each - from both continents - from all the $250 \mathrm{~m} \times 250 \mathrm{~m}$ pixels was chosen, and analysed separately for South America and Africa. This sample was used to determine the tree cover change ( $\triangle \mathrm{TC})$ in the ecosystem structure in the last two decades as follows:

$$
\Delta \mathrm{TC}=\overline{T C}_{2017-2019}-\overline{T C}_{2000-2002}
$$

Where $\overline{T C}_{2017-2019}$ and $\overline{T C}_{2000-2002}$ represent the mean of the tree cover for the years 2017-2019 and 2000-2002, respectively. Then, we classified the sample into four classes based on mean precipitation $(\bar{P}$; Fig. 2 a and c), with each $\bar{P}$ class representing $25 \%$ of the total land area. We further separated each of these $\bar{P}$ classes into samples of tree cover gain (i.e., $\Delta \mathrm{TC} \geq 0)$ and tree cover loss $(\Delta \mathrm{TC}<0)$ (Fig. 2a and c). 
After classifying, we binned the samples into separate bins sorted by mean tree cover (i.e., $\overline{T C}_{2000-2019}$; Fig. 2a and c), such that each bin represented an equal area (i.e., 2500 sampled pixels $=156.25 \mathrm{~km}^{2}$ ). Lastly, to relate stable and unstable states with the ecosystem's structural change, the $13.4 \%$ of the bins with the highest change (i.e., highest $\Delta \mathrm{TC}_{\text {median }}$ ) from all the classes combined were categorised as unstable). Furthermore, $38.2 \%$ of the bins with lowest change (i.e., lowest $\Delta \mathrm{TC}_{\text {median }}$ ) were classified as stable. The justification behind selecting the stable and unstable regions was based on the area under the distribution curve (Supplementary Fig. 7).

Finally, these stable and unstable regions, which were analysed separately for tree cover gain and loss pixels at each $\bar{P}$ class were plotted spatially at $250 \mathrm{~m}$ resolution (Fig. 2). For example, our sample analysis suggests that the unstable region for tree cover loss in South America at $\bar{P}$ class of 0-985 mm yr $\mathrm{mm}^{-1}$ falls approximately between $40-60 \% \overline{T C}_{2000-2019}$ (Fig. 2a). This will be spatially plotted in reality (population) for all the pixels falling between $40-60 \% \overline{T C}_{2000-2019}$ at $\bar{P}$ of $0-985 \mathrm{~mm} \mathrm{yr}^{-1}$ for the pixels where $\Delta \mathrm{TC}<0$.

\section{Root zone storage capacity}

For our analysis, we have considered root zone storage capacity $\left(S_{\mathrm{r}}\right.$; derived from daily precipitation and evaporation data) to represent the intrinsic capacity of the ecosystem to absorb and adapt to water-stress conditions (defined here as a deficit in soil water availability inhibiting plant growth). $S_{\mathrm{r}}$ is the maximum amount of available subsurface moisture that vegetation can store and utilise through their roots for transpiration during dry periods (i.e., periods in which evaporation is greater than precipitation, irrespective of the seasons) ${ }^{17,19,38}$. Plants can increase their $\mathrm{S}_{r}$ by expanding their roots in the soil laterally as well as vertically. We adopted the mass-balance approach by ref. ${ }^{17}$ to derive $\mathrm{S}_{r}$ from precipitation and evaporation estimates (Supplementary Method-1 in Supplementary Information). The underlying assumption of this approach is that ecosystems would not invest in expanding their storage capacity more than necessary to bridge the water-deficits it experiences ${ }^{19}$. 


\section{Forest resilience and validation}

We adapted ref. ${ }^{1}$ methodology for determining resilience using logistic regressions (Supplementary Methods-3 in Supplementary Information). The logistic regression predicts the probability of forest (tree cover $>50 \%$ ) as a function of the independent variable. Ref. ${ }^{1}$ had only considered $\bar{P}$ as the independent variable. However, the new resilience metric proposed in this study also considered $S_{\mathrm{r}}$ as an independent variable representing the drought buffer capacity of the forest ecosystems. Here, we experimented with $\bar{P}$ and $S_{\mathrm{r}}$ independently and its combination, and chose the best performing model to represent the ecosystem state (Supplementary Table 1). We modified the $S_{\mathrm{r}}$ values for all the regions with tree cover $<30 \%$ to $99^{\text {th }}$ percentile of each continent's $S_{\mathrm{r}}$. This is because we assume that forest ecosystems will maximise their capacity (i.e., maximise $S_{\mathrm{r}}$ ) before transitioning to a savannah ${ }^{17}$. Lastly, we validate the resilience estimates of $\bar{P}$ and $\bar{P}+S_{\mathrm{r}}$ combination for both tree cover loss and gain samples separately against observed $\triangle \mathrm{TC}$ to assess the performance of our metric using spearman rank correlation. A high positive or negative spearman correlation would indicate a high strength and consistency between the resilience estimates and $\triangle \mathrm{TC}$.

Data availability: The resilience map generated during this study will be made available at PANGAEA. Other publicly available datasets that support the findings of this study are available at: (P-CHIRPS) https://data.chc.ucsb.edu/products/CHIRPS-2.0/, (E-BESS) $\mathrm{ftp}: / / 147.46 .64 .183 /$, (E-FLUXCOM) ftp.bgc-jena.mpg.de, (E-PML) https://data.csiro.au/collections/\#collection/CIcsiro:17375v2, (MOD44B_v6) https://pdaac.usgs.gov/products/mod44bv006/, (Globcover) http://due.esrin.esa.int/page globcover.php, (SPEI) https://spei.csic.es/database.html, (FireCCI51) https://geogra.uah.es/fire cci/firecci51.php.

Code availability: The python code used for the analyses presented in this study is available from GitHub: https://github.com/chandrakant6492/Ecosystems-stability-and-resilience. The python code for calculating root zone storage capacity is also available from GitHub: https:/github.com/chandrakant6492/Drought-coping-strategy.

\section{Methods references}

31. Funk, C. et al. The climate hazards infrared precipitation with stations - a new environmental record for monitoring extremes. Sci. Data 2, 150066 (2015).

32. Miralles, D. G., Brutsaert, W., Dolman, A. J. \& Gash, J. H. On the Use of the Term "Evapotranspiration". Water Resour. Res. 56, e2020WR028055 (2020).

33. Jiang, C. \& Ryu, Y. Multi-scale evaluation of global gross primary productivity and evapotranspiration products derived from Breathing Earth System Simulator (BESS). Remote Sens. Environ. 186, 528-547 (2016).

34. Zhang, Y. et al. Multi-decadal trends in global terrestrial evapotranspiration and its components. Sci. Rep. 6, 19124 (2016). 
35. Jung, M. et al. The FLUXCOM ensemble of global land-atmosphere energy fluxes. Sci. Data 6 , 74 (2019).

36. Hersbach, H. et al. The ERA5 Global Reanalysis. Q. J. R. Meteorol. Soc. 245, 111840 (2020).

37. Dimiceli, C., Carroll, M., Sohlberg, R., Kim, D. H. \& Kelly, M. MOD44B MODIS/Terra Vegetation Continuous Fields Yearly L3 Global 250m SIN Grid V006. (2017) doi:10.5067/MODIS/MOD44B.006.

38. Gao, H. et al. Climate controls how ecosystems size the root zone storage capacity at catchment scale: Root zone storage capacity in catchments. Geophys. Res. Lett. 41, 7916-7923 (2014).

Acknowledgements: CS, LWE and IF acknowledge funding from the European Research Council (ERC) project on Earth Resilience in the Anthropocene (ERA), project number ERC-2016-ADG-743080. LWE also acknowledges funding from Formas, project number 2019-01220. RE acknowledges funding from the Netherlands Organization for Scientific Research (NWO), project number 016.Veni.181.015.

Author contributions: CS and RE conceived the idea. All authors contributed to the study design and interpreting the results. CS performed the analyses, and wrote the original draft. All co-authors commented on and reviewed the manuscript.

Competing interests: The authors declare no competing interests.

Supplementary Information: Supplementary Methods 1-3, Supplementary Tables 1-2, and Supplementary Figs. 1-7. 


\title{
Supplementary Information \\ for
}

\section{Tree cover change proves stability and instability in tropical ecosystems}

\author{
Chandrakant Singh ${ }^{1,2, *}$, Ruud van der Ent ${ }^{3,4}$, Lan Wang-Erlandsson ${ }^{1,2}$, Ingo Fetzer ${ }^{1,2}$ \\ ${ }^{1}$ Stockholm Resilience Centre, Stockholm University, Stockholm, Sweden \\ ${ }^{2}$ Bolin Centre for Climate Research, Stockholm University, Stockholm, Sweden \\ ${ }^{3}$ Department of Water Management, Faculty of Civil Engineering and Geosciences, Delft \\ University of Technology, Delft, the Netherlands \\ ${ }^{4}$ Department of Physical Geography, Faculty of Geosciences, Utrecht University, Utrecht, the \\ Netherlands \\ * Author to whom any correspondence should be addressed
}

Email: chandrakant.singh@su.se 


\section{Supplementary Method-1: Root zone storage capacity calculation}

We have adopted root zone storage capacity $\left(S_{\mathrm{r}}\right)$ from $\mathrm{ref}^{17}$. For this, we first calculated the water deficit (D), which is based on daily accumulated water stress due to variable precipitation (P) and evaporation (E):

$$
D(t)=E(t)-P(t)
$$

where $t$ denotes day count since the start of the simulation. The simulation for each grid cell starts in the month with the highest mean monthly precipitation (2001-2012) and runs for a whole year. The accumulated deficit $D_{a}(t+1)$ was integrated at each one-day timestep for one year such that it is either equal to or more than the deficit of the previous timestep, but never less than zero (as excess precipitation is assumed to run off as streamflow or groundwater recharge) using:

$$
D_{a}(t+1)=\max \{0, D(t)+D(t+1)\}
$$

Since the analysis is based on the assumption that vegetation adapts and responds to the critical dry period ${ }^{19}$, we compute the largest accumulated deficit per year $D_{a, y}$ by:

$$
D_{a, y}=\max \left\{D_{a}(t+1), t=1: n-1\right\}
$$

where $n$ equals the number of days in year $y$. Since this simulation is run for a whole year using rainfall and evaporation estimates, this mass-balance methodology does consider actual seasonal dynamics of rainfall (incoming moisture flux) and evaporation (outgoing moisture fluxes considering evaporation from soil moisture, interception, transpiration and open water (see methods) at diurnal timescale.

To avoid artificially introduced transitions between different biomes, a uniform 20-year drought return period based on the Gumbel extreme value distribution ${ }^{39}$ was used to normalise all $D_{a, y}$. The Gumbel distribution ( $F(x))$ is given by:

$$
F(x)=\exp \left[-\exp \left[-\frac{(x-\mu)}{\alpha}\right]\right]
$$

Where $\mu$ and $\alpha$ are the location and scale parameter, respectively. The python package 'skextremes' ${ }^{\text {'40 }}$ was used to calculate $S_{\mathrm{r}}$ :

$$
S_{\mathrm{r}}=\overline{D_{a, y}}+K \times \sigma_{n-1}
$$

Where $K$ is the frequency factor given by:

$$
K=\frac{y_{t}-\overline{y_{n}}}{S_{n}}
$$

And $y_{t}$ is the reduced variate given by:

$$
y_{t}=-\left[\ln \left[\ln \left(\frac{T}{T-1}\right)\right]\right]
$$


Where $T$ is the drought return period (i.e., 20 years in this study), $\overline{D_{a, y}}$ is the mean annual accumulated deficit for the years 2001-2012, $\sigma_{n-1}$ is the standard deviation of the sample. Also, $y_{n}$ is the reduced mean and $S_{n}$ is the reduced standard deviation, which for $n=11$ years equal to 0.4996 and 0.9676 , respectively ${ }^{39}$.

\section{Supplementary Method-2: Perturbation trends}

Ecosystems lose their structural integrity due to both climatological and non-climatological factors (i.e., human-influenced). In this study, we only focus on environmental changes that are detectable using remotely sensed datasets. To analyse this, we considered two variables (i) fire, and (ii) drought severity. Fire modifications to the ecosystems were analysed using a global time series of burned areas (named FireCCI51; $\mathrm{km}^{2}$ ) derived from Moderate Resolution Imaging Spectroradiometer (MODIS). The data was procured for the years 2001-2019 at a resolution of $250 \mathrm{~m}$ x $250 \mathrm{~m}^{41}$. ESA Globcover dataset was used to remove pixels with human land use and non-terrestrial land cover from FireCCI51 dataset.

To analyse the drought severity, we used standardised precipitation evaporation index (SPEI) ${ }^{42}$. SPEI is the modified extension of the standardised precipitation index. It is derived from climate-based datasets and has been widely used to determine the influence of droughts with varying magnitude and duration on the natural and human-influenced systems ${ }^{6}$. SPEI integrates both rainfall (i.e., supply) and potential evaporation (i.e., demand) to capture climate trends (positive for wet and negative for dry climate). For our analysis, we experimented with different SPEI potential evaporation equations (Penman-Monteith ${ }^{43}$ and Thornthwaite ${ }^{44}$ ). However, we did not observe any significant differences between the general SPEI trends. For our study, we used present the SPEI-12 (i.e. 12-month rolling average SPEI) data derived from the Climatic Research Unit (CRU) dataset, where potential evaporation was based on the Penman-Monteith equation. The SPEI-12 data was directly procured for the years $2000-2018$ at $0.5^{\circ}$ latitude $\times 0.5^{\circ}$ longitude resolution. SPEI- 12 algorithm aggregates precipitation and potential evaporation over a period of 12 months, and is thus convenient for evaluating annual (consistent with tree cover dataset) implications of droughts.

\section{Supplementary Method-3: Forest resilience calculation}

The resilience metric is based on logistic regression adapted from ref $^{1}$, however, we also included $S_{\mathrm{r}}$ along with $\bar{P}$. We used the python package "statsmodel" 45 for our analysis. The logistic regression predicting the resilience $(f(z))$ of the rainforest ecosystem was was given by:

$$
\begin{aligned}
& f(z)=\frac{1}{1+\exp (-z)} \\
& z=a+b(\bar{P})+c\left(S_{\mathrm{r}}\right)
\end{aligned}
$$

Where $z=1$ when forest (i.e., tree cover $>50 \%$ ), and $z=0$ when savannah (i.e., tree cover $\leq 50 \%$; including grasslands and treeless state). Also, $\bar{P}$ represents mean annual precipitation, and $S_{\mathrm{r}}$ represents root zone storage capacity. 


\section{Supplementary Tables}

Supplementary Table 1 | Performance of logistic regression models considered for determining the resilience of the tropical ecosystem. The models are evaluated using (shown in increasing order of the Akaike Information Criterion (AIC) and Bayesian Information Criterion (BIC). The model with least AIC and BIC is used in this study (Fig. 4).

\begin{tabular}{r|cccc}
\multicolumn{2}{c}{ South America } & \multicolumn{2}{c}{ Africa } \\
\cline { 2 - 5 } Variables & AIC & BIC & AIC & BIC \\
\hline $\bar{P}+S_{\mathrm{r}}$ & 501772.33 & 501806.75 & 249156.25 & 249191.01 \\
$S_{\mathrm{r}}$ & 582170.43 & 582193.38 & 257513.09 & 257536.26 \\
$\bar{P}$ & 638263.45 & 638286.40 & 454887.59 & 454910.76
\end{tabular}

Supplementary Table 2 | Parameters of the logistic regression that predicts the probability of tree cover as a function of $\bar{P}$ and $S_{\mathrm{r}}$. Tree cover $>50 \%$ is considered as a high tree cover ecosystem, and tree cover $\leq 50 \%$ is considered as a low tree cover ecosystem. All parameters are statistically significant (p-value $<0.05$ ).

\begin{tabular}{r|cc}
\multicolumn{1}{c}{ Coefficient } & South America & Africa \\
\hline (Intercept) a & 0.7471 & 3.7822 \\
$($ for $\bar{P}) \mathbf{b}$ & 0.0015 & 0.0012 \\
$\left(\right.$ for $\left.S_{\mathrm{r}}\right) \mathbf{c}$ & -0.0067 & -0.0162
\end{tabular}




\section{Supplementary Figures}
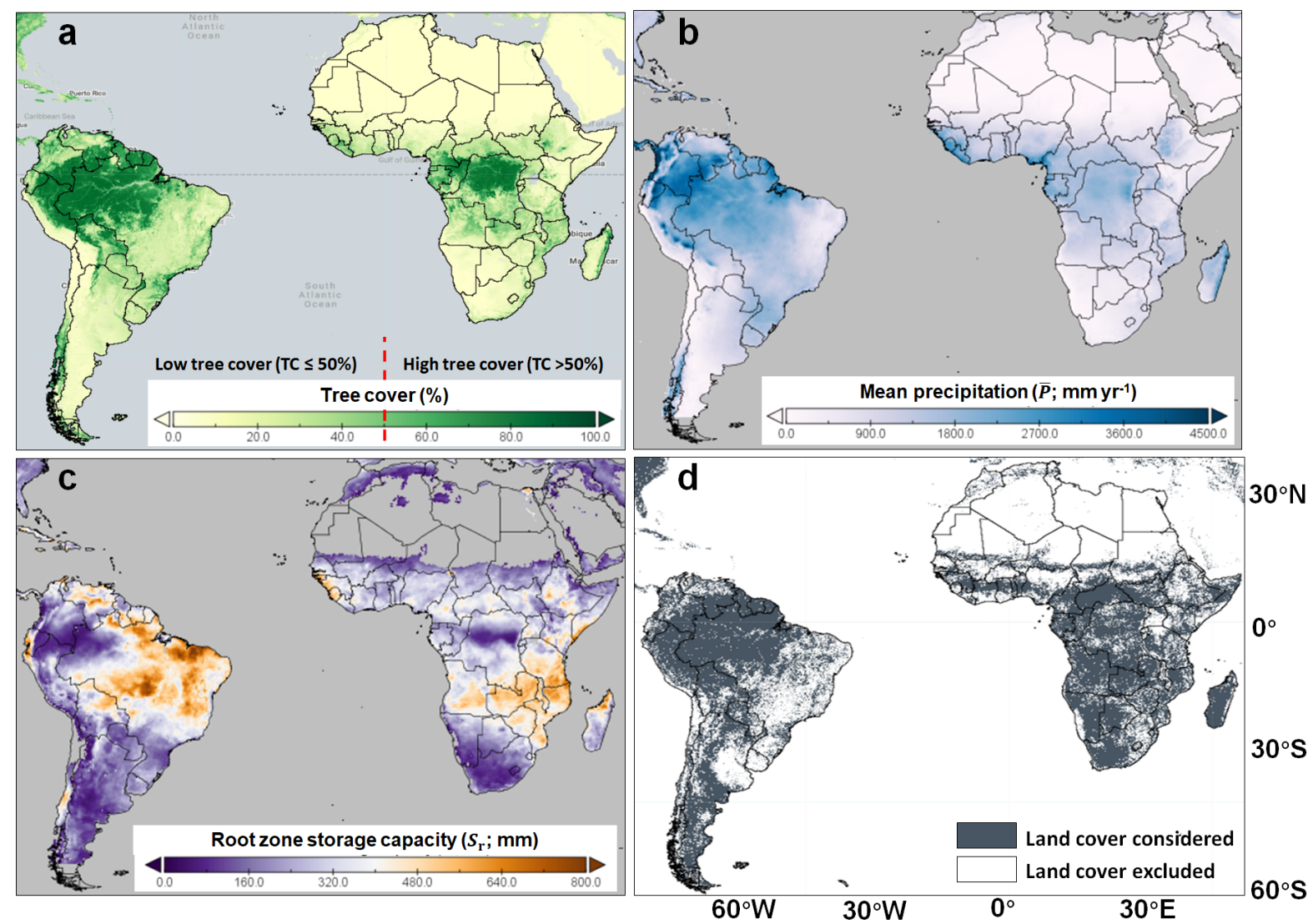

Supplementary Fig. 1 | Spatial distribution of (a) mean tree cover (from 2000-2019; \%), (b) mean precipitation (P from 2000-2019; $\mathrm{mm} \mathrm{yr}^{-1}$ ), (c) root zone storage capacity ( $\mathrm{S}_{r}$ from 2001-2012; $\mathrm{mm}$ ), and (d) land cover. 



Supplementary Fig. 2 | We observe some exceptions in South America where ecosystems do not follow the hypothesised trend of $\triangle \mathrm{TC}$ (Fig. 1a and 2). We observe that the (a) high tree cover ecosystems (not-stable; tree cover $>65 \%$ at $\bar{P}<985 \mathrm{~mm} \mathrm{yr}^{-1}$ in Fig. 2a) at the foot of the Andes (marked in red) is fed not only by local $\bar{P}$, but also gets substantial moisture from glacial runoff ${ }^{46,47}$. These ecosystems are, therefore, able to sustain themselves even at low precipitation. (b) On the other hand, low tree cover ecosystems (not-stable; tree cover < $40 \%$ at $\bar{P}>1,834 \mathrm{~mm} \mathrm{yr}^{-1}$ in Fig. 2a) between (lowland) Colombia and Venezuela (marked in red) suffers from low nutrient soil characteristics, rapid leaching and an extreme precipitation seasonality, thus promoting a savannah ecosystem even at high precipitation ${ }^{48,49}$. 

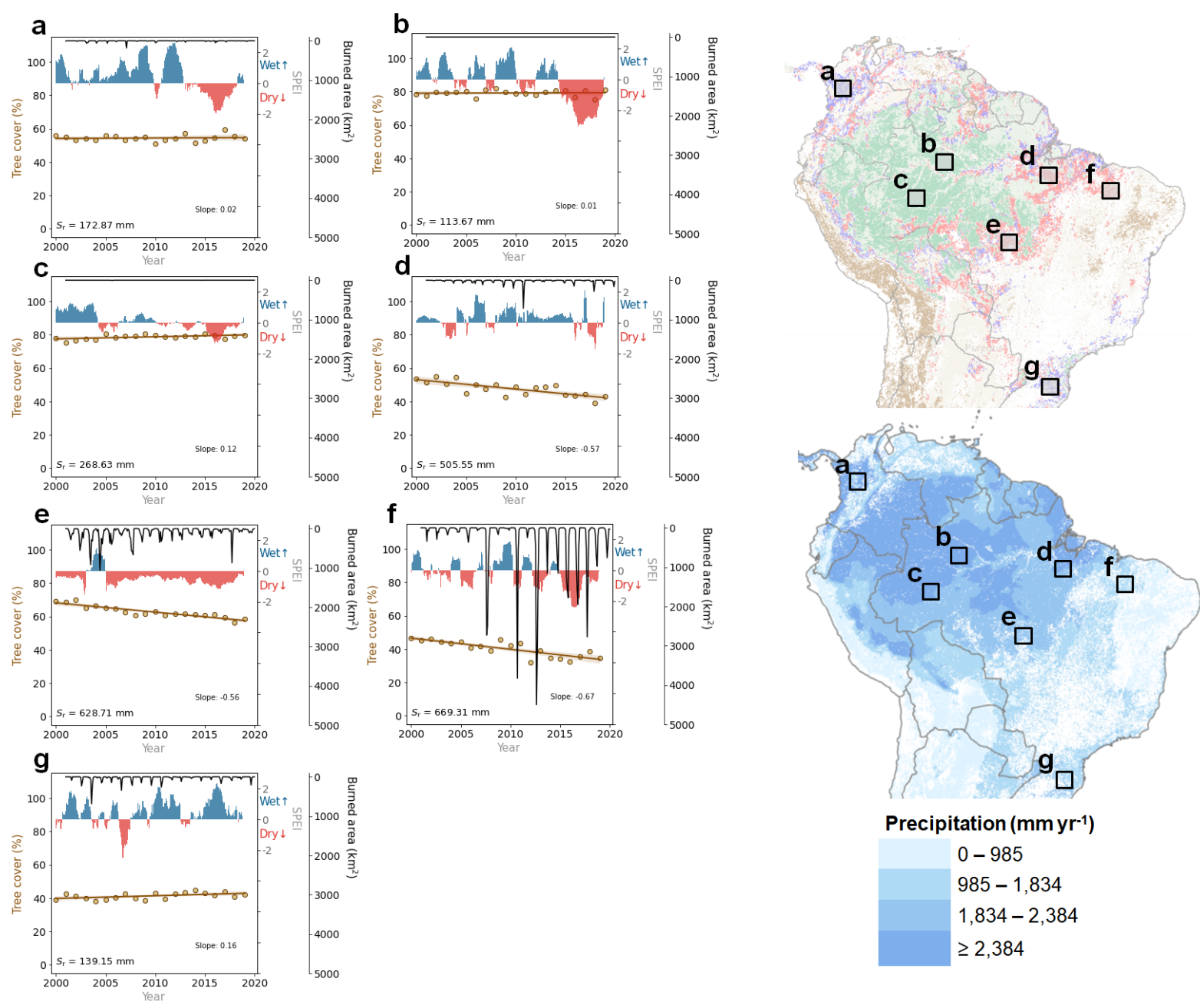

Supplementary Fig. 3 | Influence of climate and fire in influencing the tree cover of the ecosystem at different regions of interest (ROI) for South America. The regression corresponds to the changes in mean annual tree cover values in the respective ROI. The shade around the regression line corresponds to the $95 \%$ confidence interval. Here, near zero slope values signify no tree cover change, positive slopes signify a tree cover gain, and negative slopes signify a tree cover loss over time. The 12-month standardised precipitation and evaporation index (SPEI) signifies progress of the wet (positive; blue) and dry (negative; red) climate in the region. The black lines - on the top - evaluates the total burnt area due to the influence of fire in the respective ROI. 

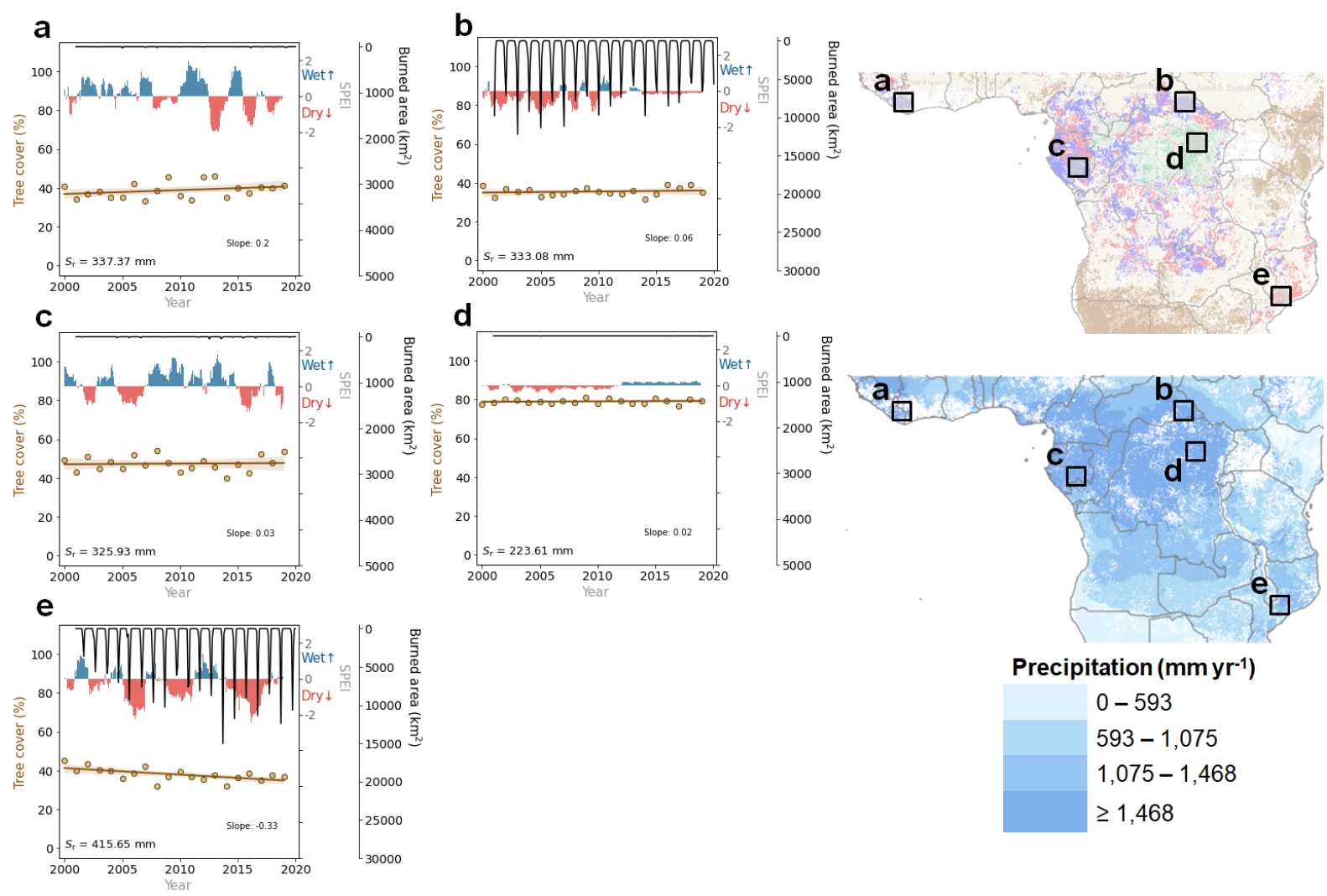

Precipitation $\left(\mathrm{mm} \mathrm{yr}^{-1}\right)$

$0-593$

$593-1,075$

$1,075-1,468$

$\geq 1,468$

Supplementary Fig. 4 | Similar to Supplementary Fig. 4, the influence of climate and fire in influencing the tree cover of the ecosystem at different regions of interest (ROI) for Africa. 



Supplementary Fig. 5 | Resilience of the ecosystem derived from precipitation $(\bar{P}$; see Supplementary Table 1) for (a) South America and (b) Africa. The spatial extent only shows the resilience for regions with tree cover $>$ $50 \%$. (c,d) Difference between the resilience used in this study $\left(\bar{P}+S_{\mathrm{r}}\right.$ in Fig. 4; Supplementary Table 1$)$ and only $\bar{P}$-derived resilience metric $(\mathrm{a}, \mathrm{b})$. 
a

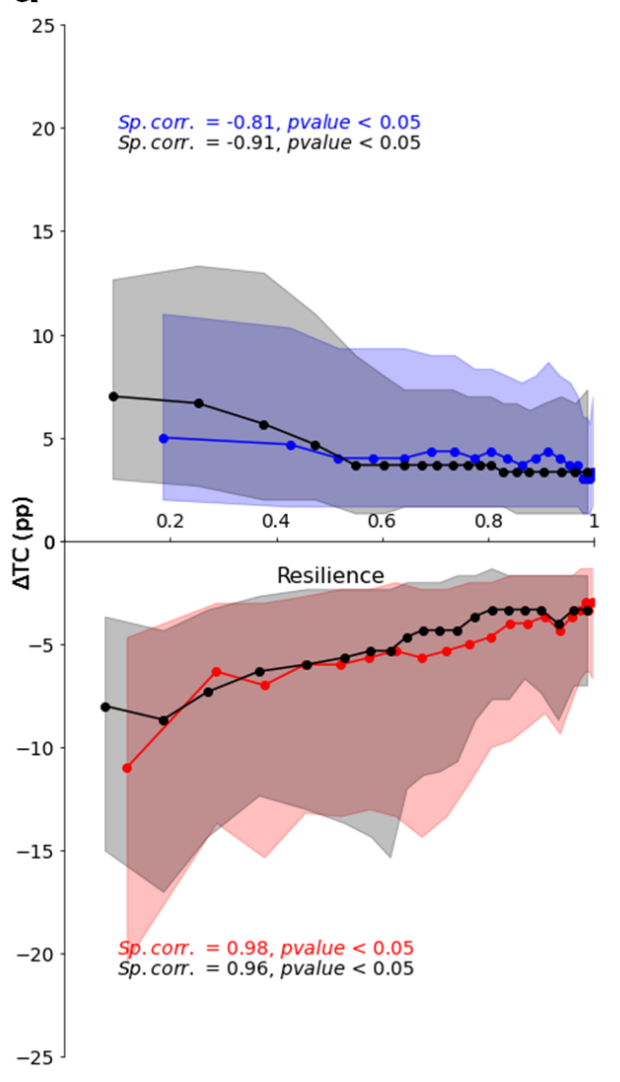

b

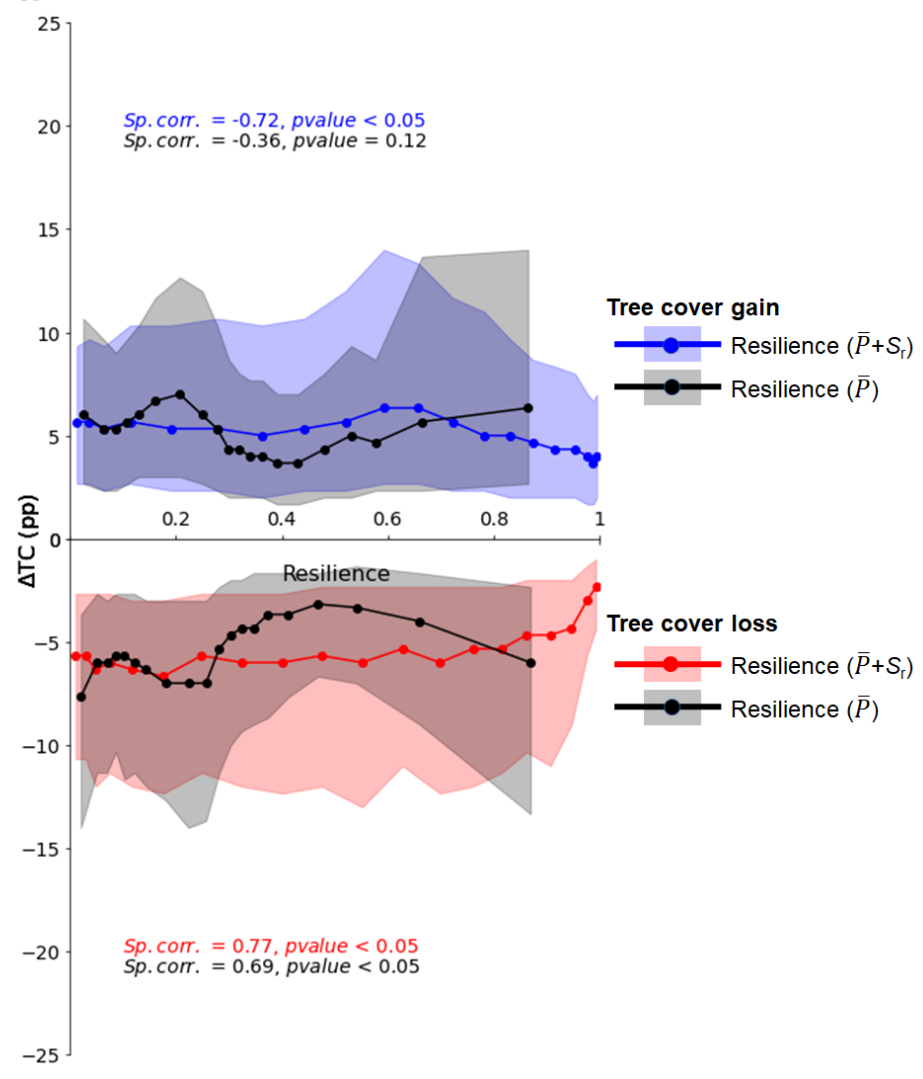

Supplementary Fig. 6 | Validating the resilience estimates of the rainforest ecosystem with actual tree cover change $(\triangle \mathrm{TC}$ ) for (a) South America and (b) Africa. The samples are divided into 20 equally-weighted intervals (similar to Fig. 2). The dots in blue (i.e., $\Delta \mathrm{TC} \geq 0$ ) and red (i.e., $\Delta \mathrm{TC}<0$ ) correspond to our $\left(\bar{P}\right.$ and $S_{\mathrm{r}}$ ) resilience metric, whereas dots in black correspond to $\bar{P}$-derived resilience estimates. The shaded regions represent the $1^{\text {st }}$ and $3^{\text {rd }}$ quantile. The statistical test calculates the spearman rank correlation (Sp.corr.) coefficient with associated p-value. 


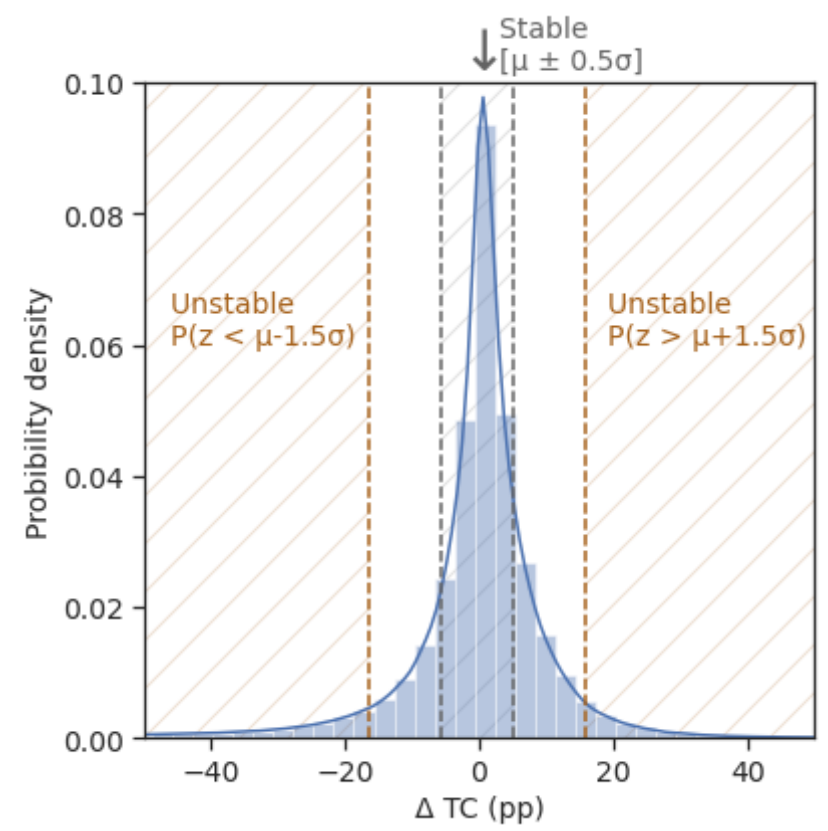

Supplementary Fig. $7 \mid$ Tree cover change ( $\triangle \mathrm{TC})$ distribution for South America. The portion within the grey and outside the brown lines represents the stable and unstable regions, respectively. Here, $P(z)$ refers to the probability distribution of the curve, $\mu$ is the mean (i.e., -0.26 ), and $\sigma$ is the standard deviation (i.e., 10.81) of the distribution. $\triangle \mathrm{TC}$ for Africa shows a similar trend, however, is not shown in this study. 


\section{Supplementary references}

39. Gumbel, E. J. Statistics of extremes. (Columbia University Press, 1958).

40. Correoso, K. skextremes Documentation. https://github.com/kikocorreoso/scikit-extremes (2019).

41. Lizundia-Loiola, J., Otón, G., Ramo, R. \& Chuvieco, E. A spatio-temporal active-fire clustering approach for global burned area mapping at $250 \mathrm{~m}$ from MODIS data. Remote Sens. Environ. 236, 111493 (2020).

42. Vicente-Serrano, S. M. et al. Response of vegetation to drought time-scales across global land biomes. Proc. Natl. Acad. Sci. 110, 52-57 (2013).

43. Allen, G. A., Pereira, L. S., Raes, D. \& Smith, M. Crop Evapotranspiration: Guidelines for computing crop water requirements. (Food and Agriculture Organization of the United Nations, Rome, 1998).

44. Thornthwaite, C. W. An Approach toward a Rational Classification of Climate. Geogr. Rev. 38, 55-94 (1948).

45. Seabold, S. \& Perktold, J. Statsmodels: Econometric and Statistical Modeling with Python. in 92-96 (2010). doi:10.25080/Majora-92bf1922-011.

46. Bradley, R. S., Vuille, M., Diaz, H. F. \& Vergara, W. Threats to Water Supplies in the Tropical Andes. Science 312, 1755-1756 (2006).

47. Herzog, S., Martinez, R., Jørgensen, P. \& Tiessen, H. Climate change and biodiversity in the tropical Andes. (Inter-American Institute for Global Change Research (IAI) and Scientific Committee on Problems of the Environment (SCOPE), 2011). doi:10.13140/2.1.3718.4969.

48. Blydenstein, J. Tropical Savanna Vegetation of the Llanos of Colombia. Ecology 48, 1-15 (1967).

49. Sarmiento, G. The Savannas of tropical America. (Elsevier, Amsterdam, The Netherlands, 1983). 